\title{
REMARKS ON THE INSECTIVORES OF THE GENUS GYMNURA.
}

\author{
By Marcus Ward Lyon, Jr.,
}

Second Assistant Curator, Division of Mammals, U. S. National Museum.

An examination of nearly two dozen specimens of the genus Gymnura in the United States National Museum shows that in addition to the two distinct species usually recognized, a third form, from the northern portion of the Malay Peninsula, must be considered. It is here described for the first time as a subspecies of the older of the two species.

As there is some lack of agreement among authors regarding the limits of the genus Gymnura, it will not be out of place to consider some of its characteristics before describing the new subspecies. Dobson, ${ }^{a}$ Flower and Lyddeker ${ }^{b}{ }^{b}$ and Trouessart ${ }^{c}$ have included under the term Gymnura certain small short-tailed species, which other writers, Thomas ${ }^{d}$ and Max Weber, ${ }^{e}$ for instance, regard as constituting a separate genus Hylomys. I quite agree with the opinion of these latter, and in order to show the distinctness of Gymnura from Hylomys figures of their skins and skulls are shown on Plates 34 to 37 . In order to make the relations of the genus Gymnura still clearer, the entire animal and the extracted skull of the unique specimen of the recently discovered and related genus Podogymnura, $f$ an animal unknown to the authors cited, are shown on the plates 36 and 37 .

Gymnura is here considered as one of three genera forming the subfamily Gymnurinæ, the other two being Hylomys and Podogymnura. In respect to size and external characteristics Hylomys and Podogymnura appear to be closely related to one another. (Plate 37.) An examination of the teeth, however (Plate 36), shows that these

${ }^{a}$ Monogr. Insectivora, 1882, p. 5.

${ }^{b}$ Introd. Study of Mammals living and extinct, 1891, p. 620.

$c$ Cat. Mamm. Suppl., 1904, p. 126.

${ }^{d}$ Ann. Mag. Nat. Hist., 6th ser., II, November, 1888, p. 407.

${ }^{e}$ Die Säugetiere, 1904, p. 379.

$f$ Mearns, Proc. U. S. Nat. Mus., XXVIII, No. 1402, p. 437, May 13, 1905.

Proceedings U. S. National Museum, Vol. XXXVI-No. 1680.

Proc.N.M.vol.xxxvi-09-29 
two genera are very distinct. The premolars both above and below in Hylomys are $\frac{4}{4}$, in Podogymnura $\frac{3}{3}$. The three anterior premolars in Hylomys are small, practically functionless teeth, while in Podogymnura the penultimate premolar is well developed and trenchant, standing nearly as high in the tooth row as the last premolar (Plate 36). The premolars in Gymnura are $\frac{4}{4}$, as they are in Hylomys. The two anterior of them are small and practically functionless, like the three anterior premolars of Hylomys; the two posterior are large and trenchant, like the two posterior premolars of Podogymnura. (Compare Plates 35 and 36.) Of the three genera Gymnura appears to be the most generalized and primitive, and from it or its ancestors the other two genera have been derived. In the shortening of the tail and simplification in the structure of the premolars IIylomys has departed further from Gymnura than has Podogymnura. The last upper molar of Podogymnura and Hylomys shows a more simple structure than the corresponding tooth of Gymnura, which has a distinct posterior heel, lacking in the other two genera. The genus Gymnura is said to present the most generalized structure known among placental mammals. ${ }^{a}$ An account of its anatomy is given in Dobson's Monograph of the Insectivora, 1882.

The geographic distribution of the genus coincides with part of the Malayan subregion of the Oriental region, namely, Tenasserim, the Malay Peninsula, Sumatra, and Borneo, and a few immediately adjacent islands. So far as known, it does not occur on others of the larger or of more remote smaller islands of the Malayan Archipelago.

Although the existence of two species in the genus had been pointed out by Giebel in $1863,{ }^{b}$ yet they were usually considered as mere local varieties, or color phases, until Jentink reaffirmed their specific distinction in 1881. ${ }^{c}$ Jentink and other writers have described certain peculiarities of shape in the skull and teeth by which the two species in the genus may be distinguished, but I have been unable to detect any other peculiarities than size and color for distingushing them. The skulls and teeth, however, show many individual variations, but none of them are constant for definite geographic areas. The characters assigned by other writers may probably be explained as the result of examining too small a number of specimens.

The different members of the genus may be distinguished by the following key:

KEY TO THE SPECIES AND SUBSPECIES OF GYMNURA.

a. Color uniformly white or whitish, size large, hindfoot 66-74 mm., basal length of skull $76-84$

Gymnura alba, p. 453

${ }^{a}$ Huxley, Proc. Zool. Soc. London, 1880, p. 657.

${ }^{b}$ Zeitschr. Ges. Naturw., XXII, p. 277.

${ }^{c}$ Notes Leyden Mus., III, pp. 166-168. 
b. Color black with some white on head and shoulders, size medium or small, hindfoot 58-68 mm., basal length of skull 67-78__Gymnura gymnura, p. 451 a. ${ }^{1}$ Size medium; hindfoot, $61-68 \mathrm{~mm}$; basal length of skull 71-78.

G. g. gymnura, p. 451 $b .^{2}$ Size small; hindfoot $58-59 \mathrm{~mm}$; basal length of skull $67-71$.

G. g. minor, p. 453

GYMNURA GYMNURA (Raffles).

Diagnostic characters.-Size small or medium; hindfoot 58-68 mm.; basal length of skull $61-78$; color generally black, with white markings on head. See fig. 3, Plate 34 .

Color.-General color black or blackish, except lips, chin, cheeks, an irregular V-shaped patch on top of head, and terminal fourth or more of tail white or whitish. About the shoulders and on upper back are numerous long hairs with long white or whitish tips. Similar hairs, but much shorter, occur on the throat.

Pelage.-The pelage is composed of two kinds of hairs, short (10-15 mm.) soft underfur of a dull blackish, brownish or dark drab-gray color, except about lips and cheeks, where it is white or whitish ; and long, coarse, bristly hair, $50-60 \mathrm{~mm}$. in length uniformly black in color, except in the region of the light markings about head and shoulders, where the long hairs are white throughout their extent or else have long white tips. About the head the long hairs are much shorter than over the rest of the body. On the underparts the long hairs are relatively few, soft, and short.

Tail.-The tail is covered with small scales about 10 to the centimeter, each scale subtended by about 3 hairs. On the dorsal surface of the tail the hairs are inconspicuous and a little longer than a scale in length; on the underside they are more conspicuous and equal 3 or 4 scales in length.

Distribution.-Tenasserim, Malay Peninsula, Sumatra.

Remarks.-This species is separable into two distinct races, a smaller one from Tenasserim, and Trong, Lower Siam, described below as new, and the typical race found on the lower end of the Malay Peninsula and on Sumatra.

\section{GYMNURA GYMNURA GYMNURA (Raffles).}

1822. Viverra gymnura Raffles, Trans. Linn. Soc. London, XIII, p. 272. (Typelocality, probably Bencoolen, Sumatra.)

1827. Gymnura rafflesii Lesson, Man. Mamm., p. 171. (May 1827. See Palmer, North Amer. Fauna, no. 23, 1904, p. 304.)

1827. Gymnura rafflesii, Honsfield and Vigors, Zool. Journ., III, p. 248, pl. viII. (October, 1827. See Palmer, North Amer. Fauna, no. 23, 1904, p. 304.)

Diagnostic characters.-A large race of Gymnura gymnura, hind foot, 61-68; basal length of skull, 71-78.

Color.-As described above under G. gymnura. 
Skull and teeth.-These are relatively large and heavy, otherwise they do not differ from those of the race described below. See fig. 2, Plate 35.

Distribution.-The U. S. National Museum contains specimens from Rumpin River, Pahang, Malay Peninsula; Singapore; Tapanuli Bay, west coast of Sumatra; the Siak region of eastern Sumatra, and Pulo Tebing Tinggi, a low alluvial island off the east coast of Sumatra. This form is probably generally distributed throughout Sumatra and the lower extremity of the Malay Peninsula.

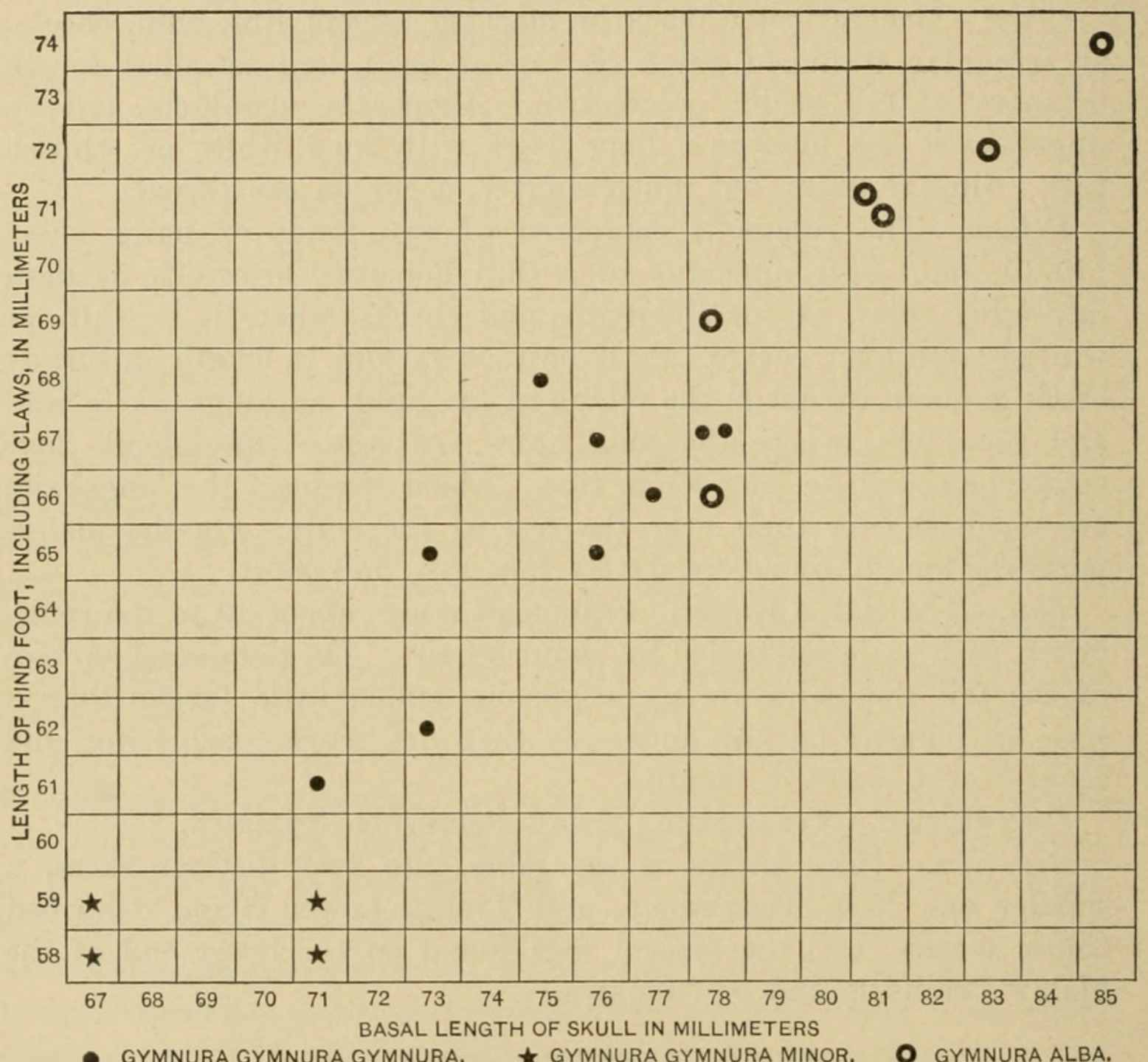

DiAgraM TO SHOW THE RELATIVE SIZES OF THE THREE FORMS IN THE GENUS GYMNURA AS DETERMINED BY LENGTH OF HIND FOOT, INCLUDING CLAWS, AND OF BASAL LENGTH OF skull. Measurements are in millimeters. Each dot represents an actual SPECIMEN,

Remarks.-What is apparently an albino specimen of this race is recorded by Schneider ${ }^{a}$ as Gymnura alba. He remarks, however, that it is distinctly smaller than white examples that he has seen from Borneo. Aside from color, difference in size is apparently the only manner by which Bornean and Sumatran examples may be distinguished. Schneider himself thought his example only a "sport." 
GYMNURA GYMNURA MINOR, new subspecies.

Type.-Skin and skull of adult male, Cat. No. 86783, U.S.N.M., collected at Trong, Lower Siam (on Khow Nok Ram, 2,000 feet altitude), January 12, 1899, by Dr. W. L. Abbott.

Diagnostic characters.- Similar in all respects to the typical race, but averaging distinctly smaller throughout. See fig. 1, Plate 34 .

Color.-The color of Gymnura gymnura minor does not differ essentially from that of $G . g$. gymnura, but there is a tendency to have more white about the head, neck, shoulders, and upper portion of back, as well as a narrower and less conspicuous black supercilliary stripe.

Skull and teeth.-These possess the same relative shapes and proportions in Gymnura gymnura minor as they do in G.g. gymnura, but a verage distinctly smaller throughout. See fig. 1, Plate 35.

Measurements.-A series of four adults, all from Trong, give the following extremes of measurements: Head and body, 311-335 mm.; tail, 216-241; hind foot, with claws, 58-59; basal length of skull, 67-71; upper tooth row (all teeth, alveoli), 40-42. See table, page 455 .

Specimens examined.-Four from the type-locality, 2 from an altitude of 2,000 feet, 1 from 1,000 feet. The altitude for the remaining specimen is not known.

Distribution.-Trong, Lower Siam, extending northward into Tenasserim. The small size of individuals from the latter country has been mentioned by both Dobson ${ }^{a}$ and Blandford. ${ }^{b}$ Bonhote $^{c}$ remarks that "the Malayan form appears to be smaller than the Sumatran race."

\section{GYMNURA ALBA Giebel.}

1863. Gymnura alba GIEBEL, Zeitschr. Ges. Naturw., XXII, 1863, p. 277. Typelocality, Borneo.)

1876. Gymnura rafflesii var. candida GüNther, Proc. Zool. Soc. London, 1876, p. 425. (Type-locality, "Labuan, the mainland opposite Labuan, and Sarawak," Borneo.)

Diagnostic characters.-Color entirely white or essentially so, largest member of the genus, hind foot $66-73 \mathrm{~mm}$., basal length of skull, 78-85.

Color.-Everywhere white or dirty white or cream color, with the exception of a few long hairs on the back which have long black tips. See fig. 2, Plate 34.

Pelage and tail.-Except for color these have the same characters in Gymnura alba that they do in G. gymnura.

a Monogr. Insectivora, p. 4.

${ }^{b}$ Fauna British India, Mammals, p. 221.

c Journ. Fed. Malay Sates Mus., III, p. 3, 1908. 
Skull and teeth.-These possess the same relative shapes and proportion as they do in Gymnura gymnura, but are distinctly larger throughout. See fig. 3, Plate 35.

Measurements.-See table, page 455, and diagram, page 452.

Distribution.-Borneo and the off-lying island of Labuan. Specimens in the U. S. National Museum are from along the Sempang River, southwestern Borneo.

Remarks.-I have been unable to find any constant character, aside from size and color, to distinguish between Gymmura gymnura and G. alba.

As in point of size the two species of Gymnura overlap one another slightly, it would be impossible to identify positively a large albino specimen of $G$. gymnura or a small individual of $G$. alba. A black individual is mentioned by Dobson ${ }^{a}$ as possibly coming from Borneo. The size relationships of the three forms on the basis of hind foot and basal length of skull are shown by the diagram, page 452 .

${ }^{a}$ Monogr. Insectivora, p. 4. 
No. 1680. INSECTIVORES OF THE GENUS GYMNURA-LYON.

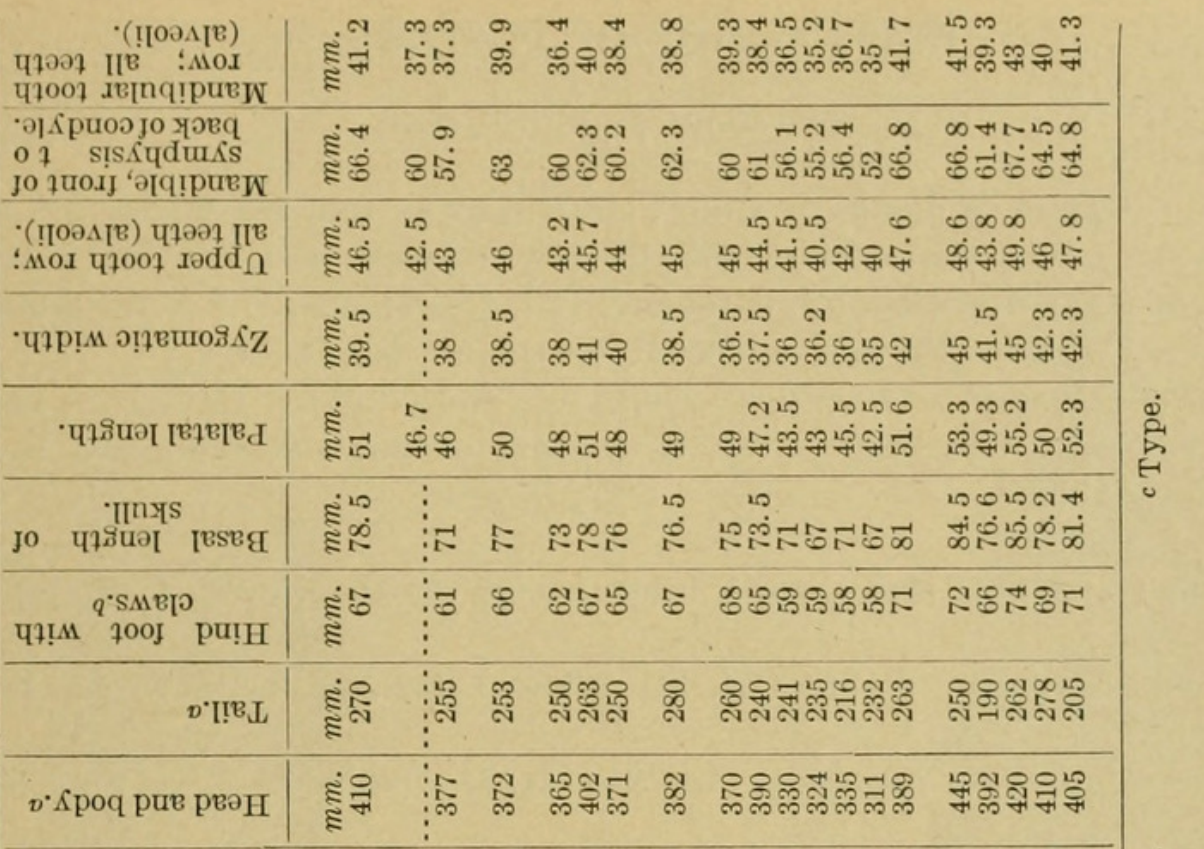

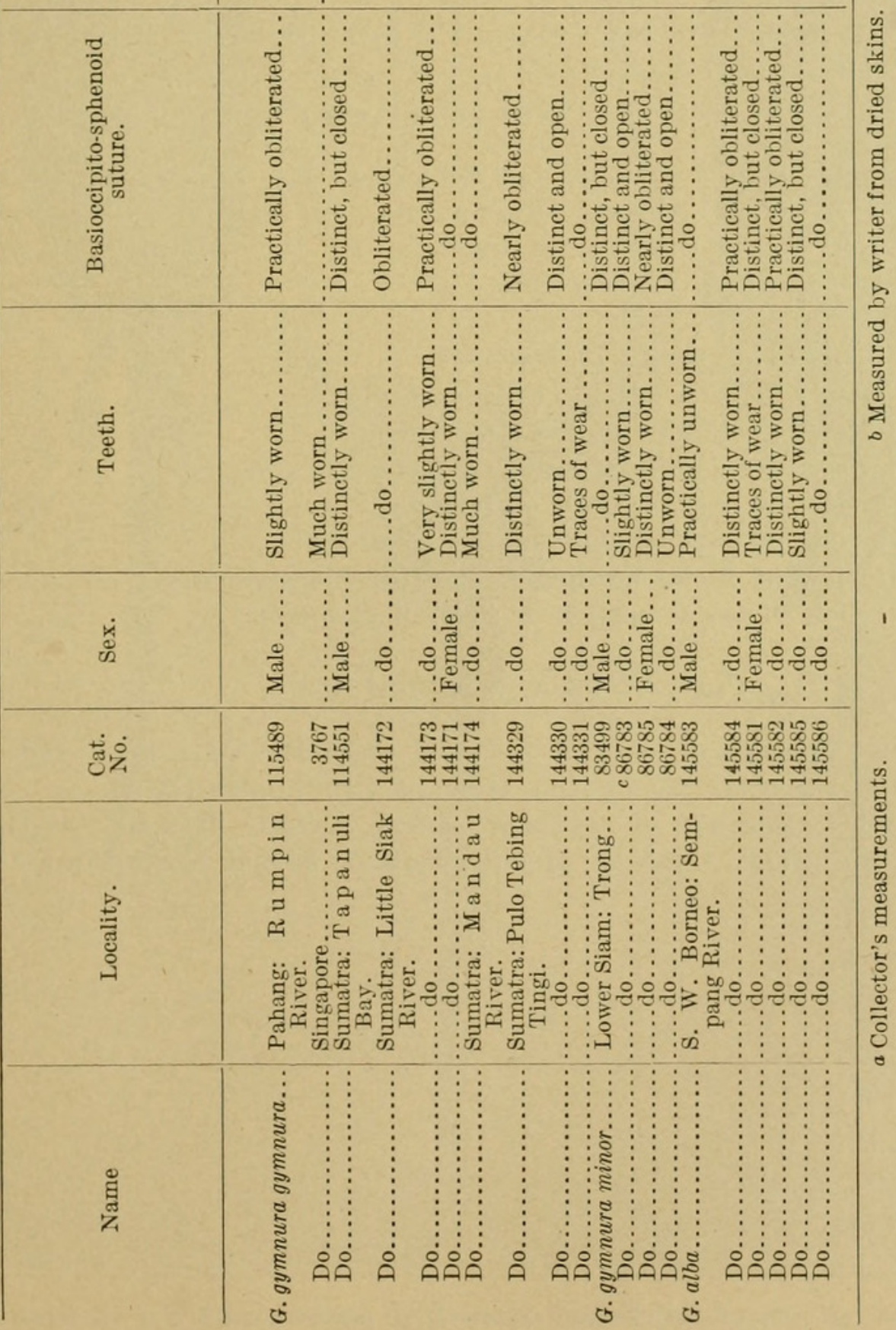




\section{EXPLANATION OF PLATES.}

Plate 34 (about $\frac{1}{4}$ natural size).

Fig. 1. Skin of Gymnura gymnura minor, adult female, Cat. No. 86784, U.S.N.M., Trong, Lower Siam, 2,000 feet altitude, collected by Dr. W. L. Abbott.

2. Skin of Gymnura alba, adult female, Cat. No. 145585, U.S.N.M., Sempang River, western Borneo, collected by Dr. W. L. Abbott.

3. Skin of Gymnura gymnura gymnura, adult male, Cat. No. 144173, U.S.N.M., Little Siak River, east coast of Sumatra, collected by Dr. W. L. Abbott.

Plate 35 ( $\frac{2}{3}$ natural size, dorsal, lateral, and ventral views of skulls).

Fig. 1. Gymnura gymnura minor, Cat. No. 86783, U.S.N.M. Type, Trong, Lower Siam.

2. Gymnura gymnura gymnura, Cat. No. 144171, U.S.N.M., Little Siak River, Sumatra.

3. Gymnura alba, Cat. No. 145584, U.S.N.M., Sempang River, western Borneo.

Plate 36 (twice natural size).

Skulls of Hylomys suillus (Müller and Schlegel), Cat. No. 124229, U.S.N.M., Tenasserim, Dr. W. L. Abbott, collector, and Podogymnura truei Mearns. Type, Cat. No. 125286, U.S.N.M., Mount Apo, Mindinao, Philippine Islands, Dr. E. A. Mearns, U. S. A., collector.

Fig. 1: Right mandibular ramus of Hylomys.

2. Right mandibular ramus of Podogymnura.

3. Dorsal view of mandibular teeth of Hylomys.

4. Dorsal view of mandibular teeth of Podogymnura.

5. Palatal view of part of skull of Hylomys.

6. Palatal view of part of skull of Podogymnura.

7. Lateral view of facial portion of skull of Podogymnura.

8. Lateral view of facial portion of skull of Hylomys.

\section{Plate 37 (about $\frac{5}{7}$ natural size).}

Fig. 1. External appearance of Podogymmura truei Mearns. Type, Cat. No. 125286, U.S.N.M., Mount Apo, Mindanao, Philippine Islands.

2. External appearance of Hylomys suillus dorsalis Thomas. Topotype, Cat. No. 124328, U.S.N.M., Mount Kinabalu, British North Borneo. 


\section{$2 \mathrm{BHL}$ Biodiversity Heritage Library}

Lyon, Marcus Ward. 1909. "Remarks on the insectivores of the genus Gymnura." Proceedings of the United States National Museum 36(1680), 449-456. https://doi.org/10.5479/si.00963801.36-1680.449.

View This Item Online: https://www.biodiversitylibrary.org/item/53526

DOI: https://doi.org/10.5479/si.00963801.36-1680.449

Permalink: https://www.biodiversitylibrary.org/partpdf/52555

\section{Holding Institution}

Smithsonian Libraries

\section{Sponsored by}

Smithsonian

\section{Copyright \& Reuse}

Copyright Status: Public domain. The BHL considers that this work is no longer under copyright protection.

This document was created from content at the Biodiversity Heritage Library, the world's largest open access digital library for biodiversity literature and archives. Visit BHL at https://www.biodiversitylibrary.org. 